\title{
THE EFFECT OF LIPOSOMAL EPIGALLOCATECHIN GALLATE AND METOCLOPRAMIDE HYDROCHLORIDE CO-ADMINISTRATION ON EXPERIMENTAL MIGRAINE
}

\author{
ADRIANA ELENA BULBOACĂ ${ }^{1}$, ALINA PORFIRE ${ }^{2}$, CRISTINA BARBĂLAT $\breve{A}^{2}$, SORANA D. \\ BOLBOACA $^{3} *$, CRISTINA NICULA ${ }^{4}$, PAUL MIHAI BOARESCU ${ }^{1}$, IOANA STĂNESCU ${ }^{5}$, \\ GABRIELA DOGARU ${ }^{6}$
}

\author{
"Iuliu Hațieganu” University of Medicine and Pharmacy, Cluj-Napoca, Romania \\ ${ }^{I}$ Department of Pathophysiology \\ ${ }^{2}$ Department of Pharmaceutical Technology and Biopharmaceutics \\ ${ }^{3}$ Department of Informatics and Biostatistics \\ ${ }^{4}$ Department of Ophthalmology \\ ${ }^{5}$ Department of Neurosciences \\ ${ }^{6}$ Department of Medical Rehabilitation
}

*corresponding author: sbolboaca@umfcluj.ro

\begin{abstract}
Epigallocatechin gallate (EGCG) has been intensively studied for its anti-oxidative, anti-inflammatory and anti-nociceptive effects. Our study aimed to assess the beneficial effect of liposomal EGCG (L-EGCG) co-administered with metoclopramide (MC) on oxidative stress and pain in experimental migraine induced by i.p. nitroglycerine (NG) administration in rats. Five groups of randomly divided rats (7/group) were investigated: control (C, group 1) with i.p. administration of saline solution, $\mathrm{NG}$ control group (group 2), $\mathrm{NG}+\mathrm{MC}$ (group 3), $\mathrm{NG}+\mathrm{MC}+\mathrm{EGCG}$ group (group 4), and $\mathrm{NG}+\mathrm{MC}+\mathrm{L}-\mathrm{EGCG}$ (group 5). The nociception was appreciated by the formalin test and the oxidative stress/anti-oxidant status by serum tests. MC alone significantly improved the nociception process and the oxidative stress parameters but not the antioxidative status. Adding EGCG to MC significantly reduced the oxidative stress and antioxidant status together with decreasing of nociception, with better results for L-EGCG.
\end{abstract}

\section{Rezumat}

Galatul de epigalocatehină (EGCG) a fost studiat pentru proprietățile sale antioxidante, antiinflamatoare și antinociceptive. Scopul prezentului studiu a fost de a evalua efectele preparatului lipozomal de EGCG (L-EGCG) adăugat la tratamentul cu metoclopramid (MC) asupra stresului oxidative și nocicepției în migrena indusă experimental la șobolani prin administrarea i.p. (intraperitoneală) de nitroglicerină (NG). Au fost analizate 5 grupuri de şobolani (7 animale/grup) la care s-au administrat i.p. următoarele preparate: grupul 1 (grupul control - administrare de ser fiziologic), grupul 2 (administrare de NG), grupul 3 (administrare de $\mathrm{NG}+\mathrm{MC}$ ), grupul 4 (administrare de $\mathrm{NG}+\mathrm{MC}+\mathrm{EGCG}$ ) şi grupul 5 (administrare de $\mathrm{NG}+\mathrm{MC}+\mathrm{L}-\mathrm{EGCG}$ ). Procesul nociceptiv a fost cuantificat prin testul cu formalină, iar stresul oxidativ prin cuantificarea parametrilor plasmatici. Tratamentul cu MC a redus semnificativ stresul oxidativ și nocicepția, dar nu a modificat semnificativ statusul antioxidant. Adăugarea de EGCG la MC a produs modificări semnificative pentru stresul oxidativ/statusul antioxidant al plasmei și procesul nociceptiv, cu rezultate mai bune pentru preparatul lipozomal.

Keywords: experimental migraine, epigallocatechin gallate, oxidative stress, liposomes

\section{Introduction}

Migraine is one of the disabling disorders and acute or prophylactic treatment of migraine attack is still under research [35]. Improving the medication strategies is important since existing treatments have their limitations: triptans can be improper for patients with cardiovascular pathologies, non-steroidal antiinflammatory drugs (NSAID) have various contraindications and calcitonin-gene related peptide (CGRP) receptors antagonists, the newly approved therapies, have a high efficacy only as a prophylactic treatment $[24,39]$. Oxidative stress proved an important contributor to migraine pathophysiology; therefore, reducing the oxidative stress intensity associated with migraine attack could improve the existing migraine treatments [9]. Oxidative stress molecules can contribute to the initiation and persistence of migraine pain, and even to the transformation in chronic pain, by influencing the nociceptive mechanism [3]. Metoclopramide (MC) is one of the choice medications for migraine attack, being widely used due to its ability to reduce the pain and to suppress one of the most critical migraine associated symptom, i.e. nausea, having comparable effects with triptans [2]. 
FARMACIA, 2019, Vol. 67, 5

One of the most important constituents released during a migraine attack, nitric oxide (NO) is used as a molecule able to induce experimental migraine and hyperalgesia in rats, by nitroglycerin administration (NO donor) [31].

Natural compounds with anti-inflammatory and antioxidant proprieties are intensively studied [23, 28]. Among natural compounds, curcumin has previously been studied in addition to sumatriptan treatment, naproxen treatment or alone and proved efficient in experimental migraine due to its anti-oxidant and antiinflammatory properties [4-6]. Epigallocatechin gallate (EGCG), another natural compound from green tea extracts, contains in its molecule a flavanol core and two gallocatechol rings that are responsible for trapping the free radicals from the environment [21]. The EGCG antioxidant activity is mostly related to hydroxyl and galloyl groups inside the structure of catechins. Thus, EGCG was proved to have more efficient antioxidant properties than vitamin $\mathrm{C}$ and $\mathrm{E}$ $[13,33]$. Moreover, EGCG is already demonstrated to be able to cross the blood-brain barrier and to exert its activity in brain parenchyma [27]. The nanoformulation of natural compounds can facilitate their pharmacological properties in order to offer a better efficiency [38]. EGCG nanoformulation could bring new benefits by improving its therapeutical properties [12]. The aim of this study was to investigate the improvement of nociception process, the changing of oxidative stress parameters (malondialdehyde, nitric oxide and total oxidative stress levels in plasma) and of the antioxidative capacity (assessed by measuring of catalase level and total antioxidant capacity of plasma) by co-administration of liposomal-EGCG and MC in an experimental migraine model induced by nitroglycerin rats.

\section{Materials and Methods}

Materials. Metoclopramide hydrochloride was purchased from Sigma-Aldrich (St Louis, MO, USA), and nitroglycerin from PubChem (Germany). The materials used for liposomes preparation were: $(-)$ epigallocatechin gallate (EGCG) from green tea (Sigma-Aldrich, Germany), 1,2-dipalmitoyl-sn-glycero-3-phosphocholine (DPPC) and N-(carbonyl-methoxypolyethylenglycol-2000)-1,2-distearoylsn-glycero-3phosphoethanolamine Na-salt (MPEG-2000-DSPE) (Lipoid GmbH, Germany) and cholesterol (CHO) from sheep wool (Sigma-Aldrich, Germany). All solvents and reagents were of analytic grade purity. The reagents used to quantify the oxidative stress and antioxidant status were procured from Sigma-Aldrich, Germany.

Experimental model

All animal procedures were performed after the approval of the Ethics Institutional Committee and were authorized by the Medicine and National
Veterinary authority. For the experimental model, 35 Wistar-Bratislava male rats were used (procured from the Animal Department, "Iuliu Haţieganu" University of Medicine and Pharmacy, Cluj-Napoca, Romania). The animals weighing 200 - $250 \mathrm{~g}$ were randomly divided into 5 groups ( 7 animals per each group) and were kept in polypropilene cages in light-dark regime, at a constant temperature $\left(24 \pm 2{ }^{\circ} \mathrm{C}\right)$ and humidity $(60 \pm$ $5 \%$ ). The animals were feed by free access with standard pellets ("Cantacuzino" Institute, Bucharest, Romania) and had free access to water.

One group was the control group $(\mathrm{C}$, group 1$)$ and received only i.p. saline solution $(0.9 \%$ sodium chloride). For the other four groups, migraine was induced by i.p. administration of NG solution. $30 \mathrm{~min}$ after NG administration, 3 of the groups received another i.p. injection consisting in $\mathrm{MC}$ solution (NG+MC group, group 3), MC and EGCG solution (NG+MC+EGCG group, group 4), MC and L-EGCG $(\mathrm{NG}+\mathrm{MC}+\mathrm{L}-\mathrm{EGCG}$ group, group 5), respectively. One group was not treated after $\mathrm{NG}$ administration and was considered the positive control group (NG, group 2). Each medication was dissolved in saline solution $(0.9 \%$ sodium chloride) and the volume administered i.p. was $1 \mathrm{~mL}$ [6]. The NG was administered in a dose of $1 \mathrm{mg} / 100 \mathrm{~g} \mathrm{bw} \mathrm{[6]} \mathrm{and} \mathrm{the} \mathrm{MC} \mathrm{in} \mathrm{a} \mathrm{dose} \mathrm{of} 1 \mathrm{mg} / \mathrm{kg}$ bw [7]. EGCG, in saline solution or in liposomal form, was freshly prepared and was administered in a dose of $2.5 \mathrm{mg} / \mathrm{kg}$ bw, i.p. [32].

Preparation and physicochemical characterization of EGCG-loaded liposomes

Liposomes were prepared using a modified film hydration method $[29,36]$. Lipid bilayer components in a concentration of $70 \mathrm{mM}$ (DPPC:MPEG-2000DSPE: $\mathrm{CHO}=4.75: 0.25: 1$ molar ratio), were dissolved in ethanol in a round-bottomed flask. The solvent was evaporated at $45^{\circ} \mathrm{C}$ under reduced pressure, and the resulted lipid film was hydrated at the same temperature with EGCG solution in ultrapure water, $\mathrm{pH}=5.00$. The liposomal dispersion was subsequently extruded through polycarbonate membranes with the final pore size of $200 \mathrm{~nm}$, using LiposoFast LF-50 equipment (Avestin Europe $\mathrm{GmbH}$, Germany). The un-encapsulated EGCG was removed by dialysis, using Slide-A-Lyzer cassettes with a molecular weight cut-off of $10 \mathrm{kDa}$.

The total amount of liposomal-loaded EGCG was determined by using a spectrophotometric method based on the reaction with Folin-Ciocâlteu (F-C) reagent Merck (Germany) [30]. For this, the liposomal dispersion was diluted with methanol 1:10 (v/v) and the absorbance was measured using a UV-VIS spectrophotometer (Specord 200 Plus, Analytik Jena, Germania). Liposomal size and polydispersity were determined by dynamic light scattering method with a scattering angle of $90^{\circ}$, and zeta potential by laser Doppler electrophoresis. Both analyses were performed using 
FARMACIA, 2019, Vol. 67, 5

a Zetasizer Nano ZS analyser (Malvern Instruments Co., Malvern, UK).

The liposomal EGCG concentration was about 900 $\mu \mathrm{g} / \mathrm{mL}$, corresponding to an encapsulation efficiency of over $80 \%$. Liposomes vesicles had a mean size of $170 \mathrm{~nm}$, and the polydispersity values were lower than 0.2 , showing that the vesicles are uniform and have the appropriate size for prolonged blood circulation. Additionally, the zeta potential was $-51.83 \mathrm{mV}$, which ensures a good aggregative stability.

Formalin test

For nociception assessment, the formalin test was performed $4 \mathrm{~h}$ after $\mathrm{NG}$ administration [6]. The number of flinches and shakes were counted in 2 distinct phases: phase 1 (during 1 - 5 min) after subcutaneously formalin injection, and phase 2 (for $1 \mathrm{~min}$ period, at 5 min interval, during $10-60 \mathrm{~min}$ after formalin injection) [37]. These two distinct phases corresponding to the vasodilatory effect induced by noxious stimulus (phase 1) and inflammation onset (phase 2) [15].

Oxidative stress and anti-oxidant parameters assessments

For oxidative stress/antioxidant parameters assessment, blood samples were collected from the retro-orbital sinus at the end of the experiment, followed by animal euthanasia, by cervical dislocation (under ketamine anaesthesia $5 \mathrm{mg} / 100 \mathrm{~g}$ bw, i.p. route) [18]. Oxidative stress parameters assessed in this study consisted of malondialdehyde (MDA) assessment, the indirect assessment of nitric oxide synthesis (NOX), and the total oxidative status (TOS) of plasma measurement. MDA assessment was made by using thiobarbituric acid, as previously described [20]. Briefly, serum sample $(150 \mu \mathrm{L})$, was mixed with trichloroacetic acid $40 \%(150 \mu \mathrm{L})$ and vortexed vigorously. Afterward, $300 \mu \mathrm{L} 0.6 \mathrm{~N} 7 \%$ thiobarbituric acid was added, and all the components were kept at $95^{\circ} \mathrm{C}$ for $30 \mathrm{~min}$, followed by ice cooling and centrifugation for $5 \mathrm{~min}$ at 13,000 rpm. The absorbance of each sample was determined at $530 \mathrm{~nm}$ compared with a blank [20]. NOx assessment was made by Griess reaction [10, 11]. In order to reduce the nitrate to nitrite $200 \mu \mathrm{L}$ of deproteinated plasma sample was mixed with $200 \mu \mathrm{L}$ of vanadium (III) chloride (VCl3) $(400 \mathrm{mg}$ in $50 \mathrm{~mL} \mathrm{HCl} 1 \mathrm{M}$ ) and further mixed with Griess reagent consisting in $50 \mathrm{~mL}$ sulphanilamide solution $(2 \times 25 \mathrm{~mL}), 50 \mathrm{~mL} \mathrm{~N}$-1-napthylethylenediamine dihydrochloride (NED) solution $(2 \times 25 \mathrm{~mL}), 1 \mathrm{~mL}$ nitrite standard ( $0.1 \mathrm{M}$ sodium nitrite). Each sample absorbance was measured after 45 min of incubation period (darkness medium, $37^{\circ} \mathrm{C}$ ) at $540 \mathrm{~nm}$. TOS measurement was made according to the method described by Erel [8]. The principle of the method is based on the proprieties of the oxidants present in the sample to oxidize the ferrous ion-o-dianisidine complex to ferric ion. For each sample, the procedure was as follows: $140 \mu \mathrm{L}$ of the plasma was added to $900 \mu \mathrm{L}$ of reagent 1 (contained $150 \mu \mathrm{M}$ xylenol orange,
$140 \mathrm{mM} \mathrm{NaCl}$ and $1.35 \mathrm{M}$ glycerol in $25 \mathrm{mM} \mathrm{H}_{2} \mathrm{SO}_{4}$ ) and $44 \mu \mathrm{L}$ of reagent 2 (contained $5 \mathrm{mM}$ ferrous ammonium sulphate and $10 \mathrm{mM}$ o-dianisidine dihydrochloride in $25 \mathrm{mM} \mathrm{H}_{2} \mathrm{SO}_{4}$ ). After were vortexed, the samples were incubated at room temperature for $30 \mathrm{~min}$, and absorbance was measured at $560 \mathrm{~nm}$. The total antioxidant capacity of plasma (TAC) and catalase measurements were used as parameters for antioxidative plasma status. TAC measurement was made following the method described by Erel [8]. Briefly, a mixture of $800 \mu \mathrm{L}$ reagent 1 (R1), $20 \mu 1$ serum sample and $40 \mu \mathrm{L}$ reagent 2 (R2) was kept for $10 \mathrm{~min}$ at room temperature, followed by absorbance determination at $444 \mathrm{~nm}$, compared with blank. R1 consists in xylenol orange $150 \mu \mathrm{M}, \mathrm{NaCl} 140 \mathrm{mM}$ and glycerol $1.35 \mathrm{M}$ in $25 \mathrm{mM} \mathrm{H}_{2} \mathrm{SO}_{4}$ solution, $\mathrm{pH} 1.75$ and $\mathrm{R} 2$ contains ferrous ion $5 \mathrm{mM}$ and $o$-dianisidine $10 \mathrm{mM}$ in $25 \mathrm{mM} \mathrm{H}_{2} \mathrm{SO}_{4}$ solution. The results were expressed as mmol Trolox equivalents/L (Tx Eq/L). Catalase was measured by the method described by Aebi that measures the catalase activity from the decomposition of $\mathrm{H}_{2} \mathrm{O}_{2}$ [1]. The decomposition of $\mathrm{H}_{2} \mathrm{O}_{2}$ was measured by the decrease in extinction at $240 \mathrm{~nm}$. The difference in extinction per unit time is a measure of the catalase activity. Briefly, $2000 \mu \mathrm{L}$ of potassium phosphate buffer $(50 \mathrm{mM})$ was mixed with $10 \mu \mathrm{L} \mathrm{H}_{2} \mathrm{O}_{2}$, followed by absorbance sample determination at $240 \mathrm{~nm}$ (A1). After adding $10 \mu \mathrm{L}$ serum from sample the second absorbance (A2) is assessed after $1 \mathrm{~min}$. The catalase activity is expressed as U/L and is calculated from formula: (A2-A1) $\times$ (sample total volume) $/ \varepsilon \times \mathrm{d} \times \mathrm{V}$ (where $\varepsilon$ is $\mathrm{H}_{2} \mathrm{O}_{2}$ extinction coefficient and is equal with $0.0436 \mathrm{mM}$, $\mathrm{d}=$ recipient width and is equal with $1 \mathrm{~cm}$, and $\mathrm{V}$ is serum sample volume). All the spectrophotometrical measurements were made using a Jasco V-350 UVVIS spectrophotometer (Jasco International Co, Ltd, Tokyo, Japan).

Statistical analyses

Data were analysed with Statistix10 program (Analytical Software, FL, USA), and presented as mean \pm standard deviation. Individual data (circles) and the value of the median (line) were plotted to present the trends between investigated groups. The differences between groups were tested with two-sided Mann-Whitney, and $\mathrm{P}<0.05$ was considered statistically significant.

\section{Results and Discussion}

In this study, an experimental migraine model was induced in rats by i.p. administration of $\mathrm{NG}$, a NO donor able to induce migraine and hyperalgesia in rats. Further, the ability of MC administered alone or coadministered with EGCG in solution or liposomal form, to influence the oxidative/antioxidant balance and nociception, was assessed. The oxidative stress parameters and antioxidant status were evaluated, and the results are presented in Table I, Figures 1 and 2. 


\section{Table I}

The levels of oxidative stress parameters and antioxidant capacity by groups (values are expressed as mean \pm standard deviation)

\begin{tabular}{|l|c|c|c|c|c|}
\hline \multicolumn{1}{|c|}{ Parameter } & C group & NG group & NG+MC group & NG+MC+EGCG group & NG+MC+L-EGCG group \\
\hline MDA $(\mathrm{pmol} / \mathrm{L})$ & $2.44 \pm 0.11$ & $5.79 \pm 0.14$ & $5.58 \pm 0.11$ & $5.26 \pm 0.12$ & $4.22 \pm 0.11$ \\
\hline NOx $(\mu \mathrm{mol} / \mathrm{L})$ & $16.21 \pm 0.76$ & $48.54 \pm 2.54$ & $42.94 \pm 1.4$ & $42.24 \pm 1.82$ & $34.24 \pm 1.39$ \\
\hline TOS $(\mu \mathrm{mol} / \mathrm{L})$ & $25.51 \pm 1.27$ & $48.14 \pm 1.26$ & $45.55 \pm 1.23$ & $42.43 \pm 1.29$ & $37.05 \pm 1.2$ \\
\hline Catalase $(\mathrm{U} / \mathrm{mL})$ & $20.25 \pm 1.42$ & $13.33 \pm 1.47$ & $13.52 \pm 1.22$ & $14.6 \pm 1.34$ & $16.21 \pm 0.76$ \\
\hline TAC $(\mathrm{mmol} \mathrm{Tx} \mathrm{Eq} / \mathrm{L})$ & $1.4 \pm 0.04$ & $0.74 \pm 0.1$ & $0.74 \pm 0.08$ & $0.88 \pm 0.10$ & $1.15 \pm 0.06$ \\
\hline
\end{tabular}

Administration of NG produced a significant change of all oxidative stress and antioxidant parameters $(\mathrm{P}<$ 0.001) (Table II). MC administration reduced the oxidative stress parameters but not the antioxidants (catalase and TAC), and the most relevant effect was noted on NOx concentration $(\mathrm{P}<0.001)$. Coadministration of EGCG significantly changed oxidative stress and antioxidant parameters (MDA, TOS, and TAC), compared with the group with MC treatment alone. NOx and catalase level were not significantly reduced by co-administration of EGCG and MC (Table I, Figures 1 and 2). Moreover, L-EGCG succeeded to significantly reduce oxidative stress parameters, compared with MC alone or MC associated with EGCG solution (Table I, Figure 1). By L-EGCG administration, the best results were obtained for all the oxidative stress parameters among all treated groups, while the catalase level was the least affected from all studied parameters (Table I, Figure 2).
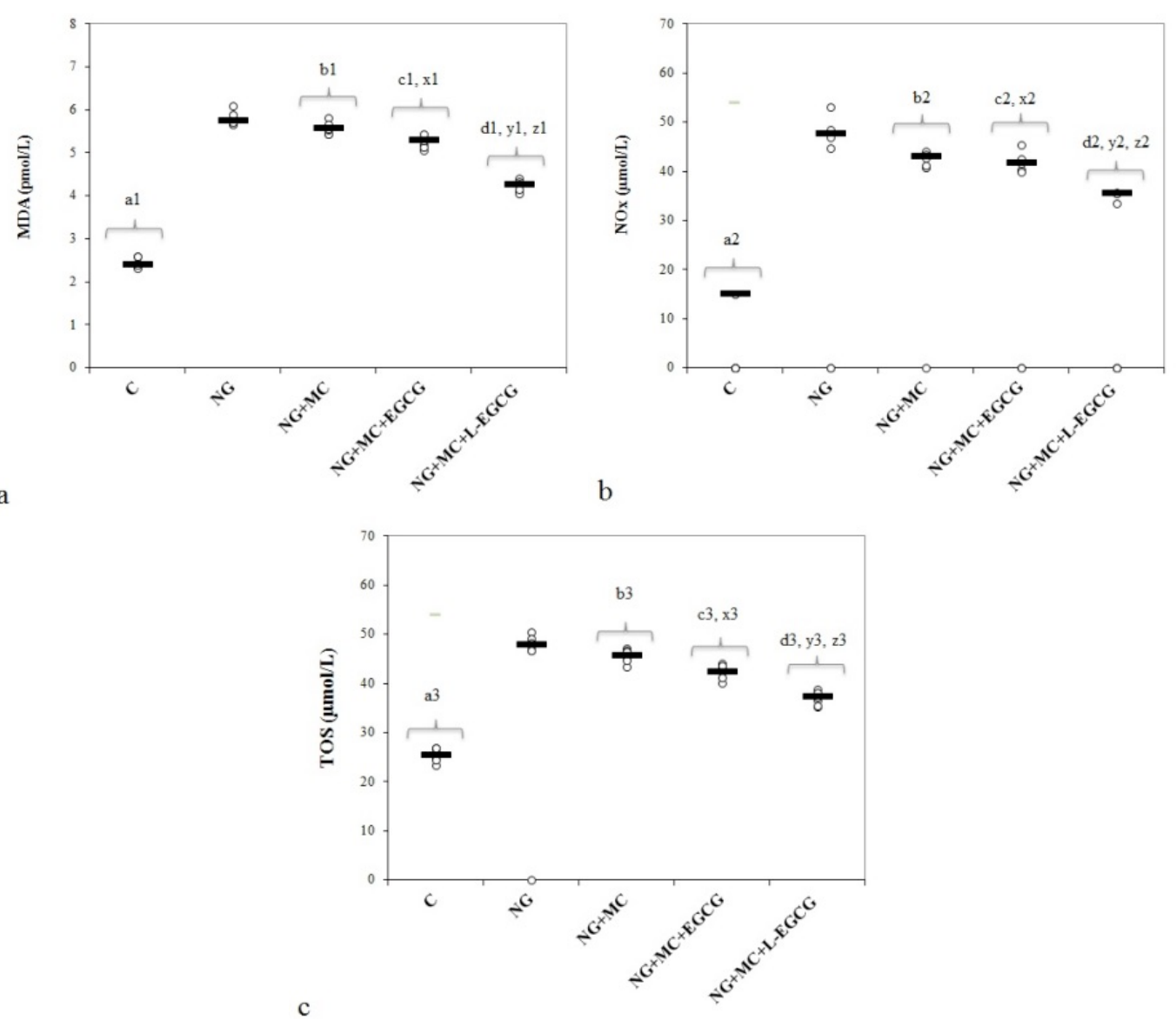

Figure 1.

Distribution of oxidative stress intensity by groups: (a) MDA (malondialdehyde), (b) NOx (nitric oxide), (c) TOS (total oxidative status). The horizontal line is given by the median, and the circles represent the individual values. $\mathrm{C}=\mathrm{C}$ Control group $\mathrm{NG}=\mathrm{NG}$ control group with nitroglycerine i.p. administration; $\mathrm{NG}+\mathrm{MC}=\mathrm{NG}$ plus metoclopramide i.p. administration group; $\mathrm{NG}+\mathrm{MC}+\mathrm{EGCG}=\mathrm{NG}$ plus $\mathrm{MC}$ co-administered with epigallocatechin gallate solution by i.p. route; $\mathrm{NG}+\mathrm{MC}+\mathrm{L}-\mathrm{EGCG}=\mathrm{NG}$ plus MC co-administered with liposomal-EGCG by i.p. route. The letter-number codes correspond to the p-values as follows: C compared to NG: ${ }^{\mathrm{a} 1-\mathrm{a} 3}<0.001 ; \mathrm{NG}+\mathrm{MC}$ compared to NG: ${ }^{\mathrm{b} 1} 0.008345,{ }^{\mathrm{b} 2}<0.001,{ }^{\mathrm{b} 3} 0.002 ; \mathrm{NG}+\mathrm{MC}+\mathrm{EGCG}$ compared to NG: $:^{\mathrm{cl}-\mathrm{c3}}<0.001,{ }^{\mathrm{c} 2} 0.001$; $\mathrm{NG}+\mathrm{MC}+\mathrm{L}-\mathrm{EGCG}$ compared to NG: ${ }^{\mathrm{d} 1}<0.001 ; \mathrm{NG}+\mathrm{MC}+\mathrm{EGCG}$ compared to NG+MC: ${ }^{\mathrm{x} 1}<0.001,{ }^{\mathrm{x} 2} 0.236,{ }^{\mathrm{x}}<0.001 ; \mathrm{NG}+\mathrm{MC}+\mathrm{L}-\mathrm{EGCG}$ compared to NG+MC: ${ }^{\text {:1-y3 }}<0.001 ; \mathrm{NG}+\mathrm{MC}+\mathrm{EGCG}$ compared to NG+MC+L-EGCG: ${ }^{\mathrm{zl}-\mathrm{z3}}<0.001$. 


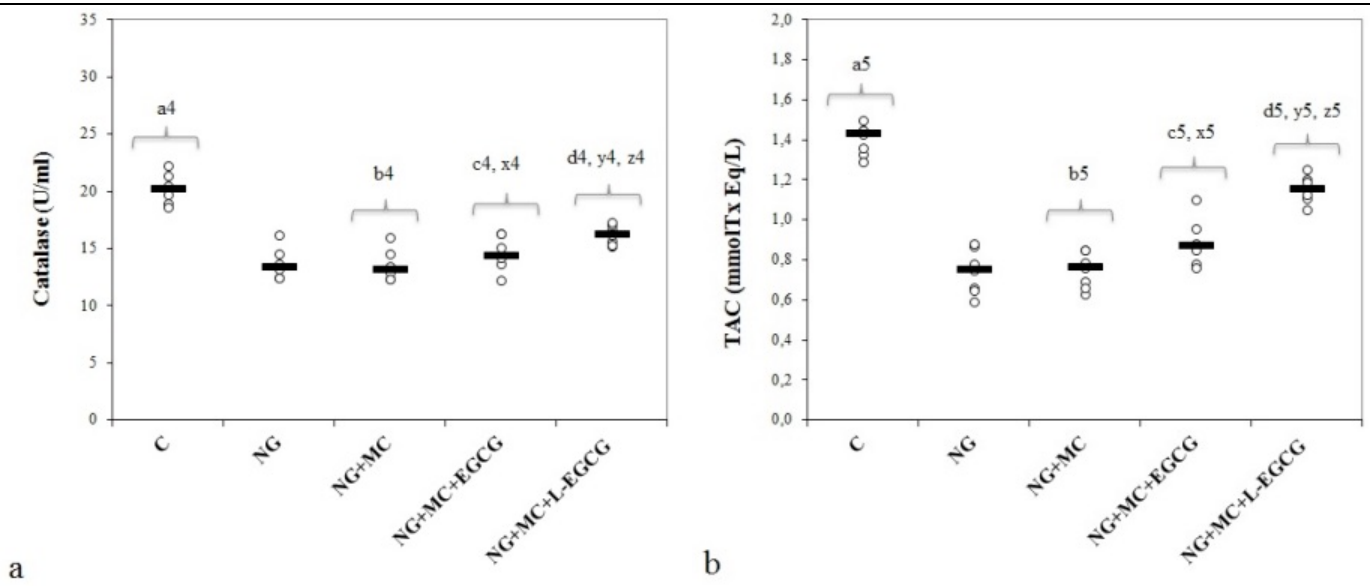

Figure 2.

Distribution of antioxidant capacity (a) Catalase and (b)TAC (total antioxidant capacity)) by groups. The horizontal line is given by the median, and the circles represent the individual values.

$\mathrm{C}=$ Control group; $\mathrm{NG}=\mathrm{NG}$ control group with nitroglycerine i.p. administration; $\mathrm{NG}+\mathrm{MC}=\mathrm{NG}$ plus metoclopramide i.p. administration group; $\mathrm{NG}+\mathrm{MC}+\mathrm{EGCG}=\mathrm{NG}$ plus $\mathrm{MC}$ co-administered with epigallocatechin gallate solution by i.p. route; $\mathrm{NG}+\mathrm{MC}+\mathrm{L}-\mathrm{EGCG}=\mathrm{NG}$ plus MC co-administered with liposomal-EGCG by i.p. route. The letter-number codes correspond to the p-values as follows: $\mathrm{C}$ compared to NG: ${ }^{\mathrm{a} 4-\mathrm{a} 5}<0.001 ; \mathrm{NG}+\mathrm{MC}$ compared to NG: ${ }^{\mathrm{b} 4} 0.407,{ }^{\mathrm{b} 5}<0.001 ; \mathrm{NG}+\mathrm{MC}+\mathrm{EGCG}$ compared to NG: ${ }^{\mathrm{c} 4}<0.001,{ }^{\mathrm{c} 5}<0.001 ; \mathrm{NG}+\mathrm{MC}+\mathrm{L}-\mathrm{EGCG}$ compared to NG: ${ }^{\mathrm{d} 4}<0.001,{ }^{\mathrm{d} 5}<0.001 ; \mathrm{NG}+\mathrm{MC}+\mathrm{EGCG}$ compared to NG+MC: ${ }^{\mathrm{x4}} 0.086,{ }^{\mathrm{x} 5} 0.014 ; \mathrm{NG}+\mathrm{MC}+\mathrm{L}-\mathrm{EGCG}$ compared to NG+MC: ${ }^{\mathrm{y} 4}<0.001,{ }^{\mathrm{y} 5}<0.001 ; \mathrm{NG}+\mathrm{MC}+\mathrm{EGCG}$ compared to NG+MC+L-EGCG: ${ }^{24} 0.013,{ }^{25}<0.001$.

Regarding the antinociceptive effect, for phase 1, comparing the control group with NG administration group, the number of flinches and shakes were significantly increased $(\mathrm{P}<0.001)$ in $\mathrm{NG}$ group, being consistently reduced by $\mathrm{MC}$ administration alone or in combination with EGCG or L-EGCG (Table II, Figure 3). Comparing various treatments co-administered with MC, L-EGCG succeeded to have the most important effect, reducing of the numbers of flinches and shakes (Figure 3). In phase 2, only L-EGCG coadministered with MC significantly reduced the number of flinches and shakes compared with both control group or with the group treated with $\mathrm{MC}$ alone (Figure 3).

Table II

The formalin test - results by groups (number of flinches and shakes expressed as mean \pm standard deviation)

\begin{tabular}{|l|c|c|c|c|c|}
\hline & C group & NG group & NG+MC group & NG+MC+EGCG group & NG+MC+L-EGCG group \\
\hline Phase 1 & $20.14 \pm 1.45$ & $41.42 \pm 1.59$ & $33.85 \pm 1.55$ & $28.85 \pm 1.88$ & $24.85 \pm 1.2$ \\
\hline Phase 2 & $114 \pm 3.33$ & $151.57 \pm 3.84$ & $127.42 \pm 3.15$ & $125.42 \pm 3.88$ & $118.71 \pm 2.65$ \\
\hline
\end{tabular}

The sensitization process as a part of migraine pathophysiology has as an important trigger, the oxidative stress augmentation, NO being an essential part of this process. MC administration can significantly reduce the oxidative stress but is not able to improve plasma antioxidant status (Table I, Figures 1 and 2). The mechanism involved in these results could be mediated by its ability to reduce the nociception (Table II) that can contribute to oxidative stress modulation. Evidence that pain can induce the increase of oxidative stress, as a physiological response to the nociceptive process exists [26]. Co-administration of EGCG and MC results in improving the oxidative stress/antioxidant status parameters and the nociceptive process, the most efficient results being obtained for L-EGCG administration. These results are coming in addition to other studies that demonstrated the anti-nociceptive properties of EGCG molecule by different mechanisms: modulating the receptors for pro-inflammatory cytokines like interleukin-1 (IL-1) [17], decreasing the expression of tumour necrosis factor-alpha (TNF- $\alpha$ ) [19], or IL-6 and IL-8 [22]. All of these molecules that contribute to the pain pathophysiology, are suppressed due to the ability of EGCG to inhibit the NF- $\mathrm{kB}$ translocation, an important contributor to the expression of pro-inflammatory molecules [22]. In addition to its properties to reduce the pro-inflammatory cytokines, EGCG proved to reduce also the prostaglandins synthesis as PGE2, due to inhibition of cyclooxygenase-2 (COX2) expression, the intermediating mechanism being the inhibition of NF- $\kappa B$ translocation [14]. Due to its properties, EGCG is intensively studied together with other natural compounds as curcumin, resveratrol, capsaicin, quercetin, eugenol or naringenin, proving not only anti-inflammatory properties that can contribute to pain reduction, but also neuro-modulatory activities [34]. The effect of EGCG on oxidative stress, that is an inductor of inflammatory reaction, was already demonstrated [25]. Moreover, due to its anti-oxidant effects, itis able to exert a neuroprotective effect [16]. Our results are in accordance with all of these findings, showing a significant reduction of nociception in experimental migraine (Table II, Figure 3) due to EGCG ability to reduce the oxidative stress parameters 
(Table 1, Figures 1 and 2), with the most efficient results for L-EGCG formulation co-administered with MC. More experimental and clinical studies are needed to demonstrate the role of EGCG as adjuvant therapy

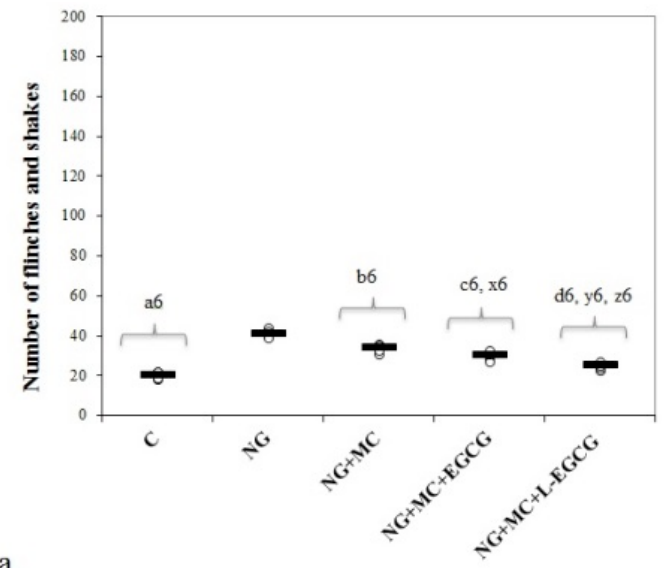

in migraine. From our knowledge, this is the first study showing EGCG and L-EGCG effects on oxidative stress and nociceptive process associated with experimental migraine.

Figure 3.

Formalin test results: (a) Phase 1 and (b) Phase 2 by groups. The horizontal line is given by the median, and the circles represent the individual values.

$\mathrm{C}=$ Control group $\mathrm{NG}=\mathrm{NG}$ control group with nitroglycerine i.p. administration; $\mathrm{NG}+\mathrm{MC}=\mathrm{NG}$ plus metoclopramide i.p. administration group; $\mathrm{NG}+\mathrm{MC}+\mathrm{EGCG}=\mathrm{NG}$ plus $\mathrm{MC}$ co-administered with epigallocatechin gallate solution by i.p. route; $\mathrm{NG}+\mathrm{MC}+\mathrm{L}-\mathrm{EGCG}=\mathrm{NG}$ plus MC co-administered with liposomal-EGCG by i.p. route. The letter-number codes correspond to the p-values as follows: C compared to NG: ${ }_{\text {a6-a7 }}<0.001 ;$ NG+MC compared to NG: ${ }^{6-b 7}<0.001 ;$ NG+MC+EGCG compared to NG: ${ }^{\text {66-c7 }}<0.001 ;$ NG+MC+L-EGCG compared to NG: ${ }^{\mathrm{d} 6-\mathrm{d} 7}<0.001 ; \mathrm{NG}+\mathrm{MC}+\mathrm{EGCG}$ compared to NG+MC: ${ }^{\mathrm{x} 6}<0.001,{ }^{\mathrm{x} 7} 0.174 ; \mathrm{NG}+\mathrm{MC}+\mathrm{L}-\mathrm{EGCG}$ compared to NG+MC: ${ }^{\mathrm{y}, \mathrm{y} 7}<0.001$; $\mathrm{NG}+\mathrm{MC}+\mathrm{EGCG}$ compared to NG+MC+L-EGCG: ${ }^{26}<0.001,{ }^{27} 0.002$.

\section{Conclusions}

The results of our study evidenced that liposomal encapsulation of EGCG enhances the antinociceptive effect of MC. Thus, nanotechnology can significantly improve the therapeutic strategies for migraine patients. The difference between EGCG solution and L-EGCG is encouraging and could bring a valuable benefit in migraine therapy. These effects have to be tested in clinical studies in order to bring evidence for their application in migraine treatment. Our results can constitute a hope for improving the symptoms of migraine patients with L-EGCG as adjuvant therapy.

\section{References}

1. Aebi H, Catalase in vitro. Methods Enzymol., 1984; 105: 121-126.

2. Barleycorn D, Systematic review: Is Metoclopramide more effective than Sumatriptan in relieving pain from migraine in adults in the Emergency Department (ED) setting?. Int Emerg Nurs., 2016; 27: 51-55.

3. Borkum JM, Migraine Triggers and Oxidative Stress: A Narrative Review and Synthesis. Headache, 2016; 56(1): 12-35.

4. Bulboacă AE, Bolboacă SD, Bulboacă AC, Porfire AS, Tefas LR, Suciu ȘM, Dogaru G, Stănescu IC, Liposomal Curcumin Enhances the Effect of Naproxen in a Rat Model of Migraine. Med Sci Monit., 2019; 25: 5087-5097.

5. Bulboacă AE, Bolboacă SD, Stănescu IC, Sfrângeu CA, Bulboacă AC, Preemptive Analgesic and Antioxidative
Effect of Curcumin for Experimental Migraine. Biomed Res Int., 2017; 2017: 1-7.

6. Bulboacă AE, Bolboacă SD, Stănescu IC, Sfrângeu CA, Porfire A, Tefas L, Bulboacă AC, The effect of intravenous administration of liposomal curcumin in addition to sumatriptan treatment in an experimental migraine model in rats. Int $J$ Nanomed., 2018; 13: 3093-3103.

7. Doğanay Aydin H, Vuralli D, Akçali DT, Bolay H, Metoclopramide inhibits trigemino vascular activation: evidence for effective acute attack treatment in migraine. Turk J Med Sci., 2017; 47(1): 343-347.

8. Erel O, A novel automated direct measurement method for total antioxidant capacity using a new generation, more stable ABTS radical cation. Clin Biochem., 2004; 37: $277-285$

9. Ferroni P, Barbanti P, Della-Morte D, Palmirotta R, Jirillo E, Guadagni F, Redox Mechanisms in Migraine: Novel Therapeutics and Dietary Interventions. Antioxid Redox Signal., 2018; 28(12): 1144-1183.

10. Giustarini D, Rossi R, Milzani A, Dalle-Donne I. Nitrite and nitrate measurement by Griess reagent in human plasma: evaluation of interferences and standardization. Methods Enzymol., 2008; 440: 361-380.

11. Goel P, Srivastava K, Das N, Bhatnagar V, The role of nitric oxide in portal hypertension caused by extrahepatic portal vein obstruction. J Ind Assoc Pediatr Surg., 2010; 15: 117-121.

12. Granja A, Frias I, Neves AR, Pinheiro M, Reis S, Therapeutic Potential of Epigallocatechin Gallate Nanodelivery Systems. Biomed Res Int., 2017; 2017: $1-15$. 
FARMACIA, 2019, Vol. 67, 5

13. He J, Xu L, Yang L, Wang X, Epigallocatechin gallate is the most effective catechin against antioxidant stress via hydrogen peroxide and radical scavenging activity. Med Sci Monit., 2018; 24: 8198-8206.

14. Heinecke LF, Grzanna MW, Au AY, Mochal CA, Rashmir-Raven A, Frondoza CG, Inhibition of cyclooxygenase-2 expression and prostaglandin E2 production in chondrocytes by avocado soybean unsaponifiables and epigallocatechin gallate. Osteoarthritis Cartilage, 2010; 18(2): 220-227.

15. Hunskaar S, Hole $\mathrm{K}$, The formalin test in mice: dissociation between inflammatory and non-inflammatory pain. Pain, 1987; 30(1): 103-114.

16. Kita T, Asanuma M, Miyazaki I, Takeshima M, Protective effects of phytochemical antioxidants against neurotoxin-induced degeneration of dopaminergic neurons. J Pharmacol Sci., 2014; 124(3): 313-319.

17. Krupkova O, Sekiguchi M, Klasen J, Hausmann O, Konno S, Ferguson SJ, Wuertz-Kozak K, Epigallocatechin 3-gallate suppresses interleukin-1beta-induced inflammatory responses in inter-vertebral disc cells in vitro and reduces radiculopathic pain in rats. Eur Cell Mater., 2014; 28: 372-386

18. Li C, Peng J, Hu R, Yan J, Sun Y, Zhang L, Liu W, Safety and Efficacy of Ketamine versus KetamineFentanyl-Dexmedetomidine Combination for Anesthesia and Analgesia in Rats. Dose Response, 2019; 17(1): 1-7.

19. Li Q, Zhang X, Epigallocatechin-3-gallate attenuates bone cancer pain involving decreasing spinal Tumor Necrosis Factor- $\alpha$ expression in a mouse model. Int Immunopharmacol., 2015; 29(2): 818-823.

20. Mitev D, Gradeva H, Stoyanova S, Petrova N, Karova N, Dimov D, Iliev V, Koychev A, Prakova G, Vlaykova $\mathrm{T}$, Evaluation of thiol compounds and lipid peroxidative products in plasma of patients with COPD. Trakia $J$ Sci., 2010; 8(Suppl. 2): 306-314.

21. Mukai K, Mitani S, Ohara K, Nagaoka S-I, Structureactivity relationship of the tocopherol-regeneration reaction by catechins. Free Radic Biol Med., 2005; 38(9): 1243-1256.

22. Ownby SL, Fortuno LV, Au AY, Grzanna MW, Rashmir-Raven AM, Frondoza CG, Expression of pro-inflammatory mediators is inhibited by an avocado/ soybean unsaponifiables and epigallocatechin gallate combination. $J$ Inflamm (Lond.), 2014; 11(1): 1-7.

23. Paltinean R, Ielciu I, Vlase L, Mocan A, Gheldiu A, Babota M, Vodnar D, Crisan G, Histo-anatomical researches plyphenolic profile and biological activities of the aerial parts and tubers of Dactylorhiza maculata L. SOÓ. (Orchidaceae). Farmacia, 2017; 6(65): 837-842.

24. Pellesi L, Guerzoni S, Pini LA, Spotlight on antiCGRP monoclonal antibodies in migraine: the clinical evidence to date. Clin Pharmacol Drug Dev., 2017; 6(6): 534-547.

25. Peluso I, Serafini M, Antioxidants from black and green tea: from dietary modulation of oxidative stress to pharmacological mechanisms. Br J Pharmacol., 2017; 174(11): 1195-1208
26. Perrone S, Bellieni CV, Negro S, Longini M, Santacroce A, Tataranno ML, Bazzini F, Belvisi E, Picardi A, Proietti F, Iantorno L, Buonocore G, Oxidative stress as a physiological pain response in full-term newborns. Oxid Med Cell Longev., 2017; 2017: 1-7.

27. Pervin M, Unno K, Nakagawa A, Takahashi Y, Iguchi K, Yamamoto H, Hoshino M, Hara A, Takagaki A, Nanjo F, Minami A, Imai S, Nakamura Y, Blood brain barrier permeability of (-)-epigallocatechin gallate, its proliferation-enhancing activity of human neuroblastoma SH-SY5Y cells, and its preventive effect on age-related cognitive dysfunction in mice. Biochem Biophys Rep., 2017; 9: 180-186.

28. Popescu ML, Costea T, Gîrdi CE, Fierăscu I, Balaci TD, Fierăscu RC, Antioxidant activity of Romanian Agaricus blazei Murrill. and Agaricus bisporus J.E. lange mushrooms. Farmacia, 2017; 65(3): 329-335.

29. Porfire A, Tomuta I, Leucuta SE, Achim M, Superoxide dismutase loaded liposomes. The influence of formulation factors on enzyme encapsulation and release. Farmacia, 2013; 61(5): 865-873.

30. Postescu ID, Tatomir C, Chereches G, Brie I, Damian G, Petrisor D, Hosu A-M, Miclaus V, Pop A, Spectroscopic characterization of some grape extracts with potential role in tumor growth inhibition. $J$ Optoelectron Adv M., 2007; 9(3): 564-567.

31. Pradhan AA, Bertels Z, Akerman S, Targeted nitric oxide synthase inhibitors for migraine. Neurotherapeutics, 2018; 15(2): 391-401.

32. Qi S, Wang C, Song D, Song Y, Intraperitoneal injection of (-)-Epigallocatechin-3-gallate protects against light-induced photoreceptor degeneration in the mouse retina. Mol Vis., 2017; 23: 171-178.

33. Rice-Evans CA, Miller NJ, Bolwell PG, Bramley PM, Pridham JB, The relative antioxidant activities of plant-derived polyphenolic flavonoids. Free Radic Res., 1995; 22(4): 375-383.

34. Singh AK, Kumar S, Vinayak M, Recent development in antihyperalgesic effect of phytochemicals: antiinflammatory and neuro-modulatory actions. Inflamm Res., 2018; 67(8): 633-654.

35. Stovner LJ, Hagen K, Jensen R, Katsarava Z, Lipton R, Scher A, Steiner T, Zwart JA, The global burden of headache: a documentation of headache prevalence and disability worldwide. Cephalalgia, 2007; 27(3): 193-210.

36. Sylvester B, Porfire A, Muntean DM, Vlase L, Luput L, Licarete E, Sesarman A, Alupei MC, Banciu M, Achim M, Tomuta I, Optimization of prednisolone loaded long circulating liposome's via application of quality by design (QbD) approach. J Liposome Res., 2018; 28(1): 49-61.

37. Tjølsen A, Berge OG, Hunskaar S, Rosland JH, Hole $\mathrm{K}$, The formalin test: an valuation of the method. Pain, 1992; 51(1): 5-17.

38. Watkins R, Wu L, Zhang C, Davis RM, Xu B, Natural product-based nanomedicine: recent advances and issues. Int J Nanomed., 2015; 10: 6055-6074.

39. Xu H, Han W, Wang J, Li M, Network metaanalysis of migraine disorder treatment by NSAIDs and triptans. J Headache Pain, 2016; 17(1): 1-18. 